УДК 330.1

DOI: $10.14451 / 1.190 .158$

\title{
АГЕНТСКАЯ ПРОБЛЕМА В ИНВЕСТИЦИОННОЙ ДЕЯТЕЛЬНОСТИ КОМПАНИИ
}

\author{
(c) 2020 Ткаченко Елена Анатольевна
}

доктор экономических наук, профессор

Санкт-Петербургский государственный экономический университет, Россия, Санкт-Петербург

E-mail: eletkachenko@ya.ru

(c) 2020 Васильев Сергей Игоревич

аспирант

Санкт-Петербургский государственный экономический университет, Россия, Санкт-Петербург

E-mail: Vasilev.sergei.12@gmail.com

Данная статья посвящена анализу агентской проблемы в инвестиционной деятельности организации. Разнонаправленность интересов собственников и менеджеров приводит к увеличению агентских издержек в данной сфере. Современные исследования посвящены поиску механизмов снижения агентских издержек в инвестиционной деятельности компании. Один из таких механизмов - концепция реальных опционов, инструмент для более полного и комплексного риск-менеджмента.

Ключевые слова: агентская проблема, риск-менеджмен, реальные опционы, ставка дисконтирования, неопределенность.

Введение. Источники агентских издержек в инвестиционной деятельности компании

Теория агентских отношений является основополагающей теорией корпоративного управления. С 1960х годов термином «корпоративное управление» (corporate governance) обозначались отношения акционеров и наёмных менеджеров [6], то есть разделение властей в организации, что является содержанием агентской проблемы [2]. Корпоративное управление (corporate governance) определяют как область теоретических и прикладных исследований, которая «имеет дело с тем, как устроена и реализуется власть (governance) в организации» [2].

М.К.Дженсен и У.Х. Меклинг [5] определили агентские отношения как «контракт, в соответствии с которым один или более человек (принципал или принципалы) привлекают другого человека (агента) для выполнения некоторых действий от своего имени, что подразумевает делегирование некоторых полномочий принятия решений агенту». Согласно определению А.В.Либмана [15], «агентская проблема (agency problem) в корпоративном управлении представляет собой противоречие интересов менеджеров и поставщиков капитала, которое возникает по причине отсутствия стремления менеджеров к максимизации доходов на инвестированные средства».
С.К.Майерс [18] писал, что, даже если за ценностью компании можно наблюдать, её величина обычно неподконтрольна менеджменту. В.Л.Окулов [8] пишет: «Нежелание идти на явный риск, излишняя осторожность менеджеров - одно из проявлений агентской проблемы, и правильно выбранный критерий, который в максимальной степени согласует интересы менеджеров и акционеров, способен уменьшить её остроту».

С одной стороны, неопределённость есть источник рисков. С другой стороны, какая неопределённость в агентских отношениях угрожает собственникам? Та, что влияет на их благосостояние,- издержки. В Таблице 1 представлена классификация источников агентских издержек в инвестиционной деятельности компании.

С точки зрения менеджмента, специфический риск, связанный с конкретной компанией, может быть снижен за счёт диверсификации деятельности, то есть, портфеля проектов компании [5]. Менеджеры будут потенциально более заинтересованы в управлении специфическими рисками компании, чем в анализе рыночных рисков, так как вознаграждение, предусмотренное контрактом, не изменится при неблагоприятных рыночных условиях, но может снизиться при худших результатах деятельности компании из-за её специфических рисков [1].

С другой стороны, собственники понимают, 
Таблица 1. Классификация источников агентских издержек в инвестиционной деятельности компании

\begin{tabular}{|c|c|c|}
\hline Источник агентских издержек & Факторы издержек & Исследования \\
\hline недоинвестирование & $\begin{array}{l}\text { - невозможность диверсифицировать специфические } \\
\text { риски; } \\
\text { - ограниченность рынков капитала; } \\
\text { - надбавки за специфический риск, блокирующие приня- } \\
\text { тие инвестиционных проектов; } \\
\text { - нежелание менеджера собирать и анализировать инфор- } \\
\text { мацию для уменьшения неопределённости; } \\
\text { - несклонность менеджера к риску; } \\
\text { - способность анализировать решения; } \\
\text { - различные горизонты принятия решений у акционеров } \\
\text { и менеджеров }\end{array}$ & {$[8,15,17]$} \\
\hline $\begin{array}{l}\text { диверсификация } \\
\text { специфических рисков }\end{array}$ & $\begin{array}{l}\text { - нежелание менеджера собирать и анализировать инфор- } \\
\text { мацию для уменьшения неопределённости; } \\
\text { - несклонность менеджера к риску }\end{array}$ & {$[8,15]$} \\
\hline сверхинвестиции & $\begin{array}{l}\text { - несклонность менеджера к риску; } \\
\text { - способность анализировать решения; } \\
\text { - сверхоптимизм; } \\
\text { - структура капитала }\end{array}$ & {$[15,17,18]$} \\
\hline избыточное хеджирование & $\begin{array}{l}\text { - структура капитала; } \\
\text { - повышение информативности финансовой отчётности; } \\
\text { - налоговые преимущества }\end{array}$ & {$[10,13,14]$} \\
\hline
\end{tabular}

что бо̀льшие риски могут при благоприятных обстоятельствах означать бо̀льшую доходность, поэтому они заинтересованы в том, чтобы компания несла бо̀льшие риски. Собственники могут диверсифицировать свой портфель между несколькими отраслями и компаниями, что снижает для них значимость специфических рисков конкретной компании $[8,1,15]$.

Е.Н.Лим, С. С.Дас и А.Дас [16] выделяют связанную диверсификацию (related diversification) компании, которая подразумевает распределение энергии и передачу навыков между различными видами деятельности компании, что приводит к росту ценности компании за счёт синергетического эффекта. Несвязанная диверсификация означает, что «менеджеры фирм с излишними денежными средствами предпринимают низкодоходную деятельность вопреки интересам акционеров вместо того, чтобы выплачивать дивиденды, так как такие выплаты сокращают ресурсы, которые они контролируют, уменьшают их власть и делают их зависимыми от удачи на внешних финансовых рынках» [16]. В частности, менеджеры могут направлять ресурсы на те проекты, которые принесут им личные экономические выгоды.

Наличие у компании долга сокращает агентские издержки, отмечают Е.Н.Лим, С.С.Дас и А.Дас [16], так как кредиторы со своей стороны контролируют деятельность компании. Так- же, как отмечал С. Майерс [18], наличие корпоративного долга может привести к тому, что менеджмент компании будет осуществлять избыточные инвестиции за счёт долгового финансирования, желая соответствовать требованиям кредиторов, что может увеличивать ценность корпоративного долга, но уменьшать благосостояние собственников компании.

Проблема недоинвестирования [15], следующая составляющая агентской проблемы, заключается в нерасположении менеджера направлять ресурсы компании на рисковые проекты по причине непредсказуемости результата, так как его вознаграждение зависит от доходности проекта. Другой причиной нежелания менеджера рисковать может быть, как анализирует Р.А. Ламберт [15], уклонение менеджера от работы по анализу рисков, что приводит к недостатку информации для оценки рисков проекта и управления ими. Следовательно, для менеджера оптимальной стратегией становится выбор наименее рискового проекта из возможных альтернатив, или отказ от проекта. А. Дамодаран [4] отмечает также ограниченность рынков капитала как причину недоинвестирования и обращает внимание на проблему избыточного хеджирования: «Поскольку именно менеджеры, а не владельцы фирм принимают решения о том, какие риски принимать и какие хеджировать, вполне возможно, что менеджеры будут хеджировать 
риски, в отношении которых владелец никогда не принял бы такого решения». Избыточное хеджирование провоцирует излишняя склонность менеджеров избегать риска и желание менеджеров произвести впечатление на инвесторов, раскрывая в отчётности компании информацию о хеджировании.

\section{Влияние агентской проблемы на практи- ку оценки инвестиционных проектов}

Агентская проблема в инвестиционной деятельности компании оказывает очень серьезное влияние на решение одной из основных задач менеджмента организаций - на оценку и выбор тех или иных инвестиционных проектов для реализации. В современных условиях эта задача становится все более и более непростой, так как уровень неопределенности во внешней среде бизнеса (да и во внутренней) очень высок. Как следствие, теория менеджмента и финансов в части оценки проектов и практика в этом направлении в определенной степени расходятся. Эти расхождения начинаются с применения различных методов и критериев оценки инвестиционных проектов, так как и в мире, и в России не все менеджеры ориентируются на критерии с учетом временной стоимости денег (критерий NPV - чистой приведенной стоимости и критерий IRR - внутренней нормы доходности), а используют, например критерий срока окупаемости и балансовой оценки рентабельности [8].

Однако даже те руководители, которые стремятся применять фундаментально обоснованные методы принятия решений на практике, по всей видимости, не полностью следуют теоретическим рекомендациям. Прежде всего, это касается оценки ставки дисконтирования. Многие менеджеры корректирует полученную из теоретических обоснований ставку, вводя дополнительные факторы риска. Также менеджеры используют и нормативную (единую для всех проектов) ставку, которая либо принимается равной средней исторической доходности по акциям компании, либо устанавливается по требованию владельца компании или регулирующих органов, либо берется с ориентацией на дивидендную доходность и бухгалтерские показатели прибыльности [12].

При этом стоит отметить, что единого мнения или системного подхода к расчету величины данной надбавки среди исследователей нет, что приводит к выбору такой надбавки совершенно произвольно на базе экспертного мнения [8].

Что касается российской практики, то корректный выбор ставки дисконтирования является еще более сложной задачей, поскольку среди теоретиков и консультантов нет единого мнения относительно модели, на основе которой можно было бы вычислить ожидаемую доходность инвестиций на развивающихся рынках [8].

Ставка дисконтирования сама по себе в определенной степени служит мерилом риска (например, инвестиционного проекта). При оценке проектов зачастую используются традиционные методы оценки и управления риском в инвестиционных проектах, а именно:

- анализ чувствительности;

- сценарный анализ;

- метод Монте-Карло.

Анализ чувствительности используется для определения степени влияния независимых переменных на зависимую с учетом определенных допущений. Например, данная техника используется для определения влияния изменений процентной ставки на цену облигаций. Анализ чувствительности позволяет прогнозировать, к чему приведет то или иное решение, если ситуация во внешней среде отклонится от заложенных ключевых предположений.

Сценарный анализ - это оценка ожидаемого значения стоимости портфеля или результата инвестиционного проекта при допущении определенных изменений в стоимости ценных бумаг, входящих в портфель, или в ключевых факторах, влияющих на инвестиционный проект.

Метод Монте-Карло используется для определения вероятности того или иного исхода при помощи многочисленных испытаний с использованием случайных переменных (так называемой симуляции) [3].

Механизмы снижения агентских издержек в инвестиционной деятельности компании

Таким образом, все рассмотренные методы оценки риска инвестиционных проектов имеют самое непосредственное значение к развитию предприятия, так как на их основе принимаются решения о реализации проектов. При этом стоит отметить несколько проблем, связанных с вышеизложенными подходами:

1. Применение нормативной (экспертной) ставки дисконтирования может привести к проблеме недоинвестирования или переинвестиро- 
вания. Так, если нормативная ставка окажется меньше требуемой акционерами справедливой доходности, то компания по критерию NPV будет инвестировать в проекты, невыгодные акционерам. Если же нормативная ставка превышает справедливую доходность, то по критерию NPV некоторые выгодные проекты будут отклонены [8].

2. Применение методов анализа чувствительности, сценарного анализа и метода МонтеКарло позволяет оценить проект при изменении вводных, однако эти методы не учитывают возможность менеджеров влиять на ситуацию при различных событиях во внешней среде.

3. Данные методы оценки риска отделены от оценки доходности проекта.

В последнее время появляются исследования, в которых предлагаются новые механизмы уменьшения агентских издержек, кроме традиционных контроля и мотивации. К таким исследованиям можно отнести предложенные В. Л. Окуловым [8] модели корректировки ставки дисконтирования, которые учитывают поведение менеджеров при принятии решений об инвестировании. Обе модели основаны на применении метода оценки рисков VaR (Value at Risk). Суть моделей заключается в определенном соотношении интересов менеджеров и акционеров, которое достигается путем выбора инвестиционных проектов, которые если не максимизируют богатство собственников, то, как минимум, либо имеют доходность не ниже рыночного портфеля, либо имеют вероятность убытков не выше рыночного портфеля. В этом случае акционеры не против таких проектов, а подобная оценка может дать обоснованную оценку надбавки к теоретической ставке дисконтирования для применения менеджерами [8].

Другим возможным механизмом решения агентской проблемы в инвестировании является применение в оценке реальных опционов.

Концепция реальных опционов позволяет учитывать влияние различных факторов риска непосредственно в процессе оценки проектов, в отличие от традиционной оценки инвестиционных проектов, которая предполагает раздельную оценку доходности проекта и его риска.

Данная концепция предполагает, что решение принимается не один раз перед началом реализации инвестиционного проекта, а несколько раз на разных стадиях его реализации после снижения уровня неопределенности, в связи с чем у менеджмента компании существенно больше гибкости для приспособления к изменениям в экономической среде [9]. Концепция корректирует недостатки метода дисконтированных денежных потоков, который в силу невозможности принять во внимание управленческую гибкость может недооценивать реальную ценность компании или инвестиционного проекта. Теория реальных опционов не отвергает идеи традиционных методов оценки, наоборот, она полагается на их результаты.

Таким образом, концепция реальных опционов - это скорее дополняющая основные инструменты методика, которая позволяет учесть возможность менеджеров принимать наилучшие решения исходя из текущих экономических условий [11].

Обычно рассматривается четыре основных типа реальных опционов:

1) возможность делать последующие инвестиции;

2) возможность выйти из проекта;

3) возможность подождать и инвестировать позже;

4) возможность изменять объем или методы производства.

Этот подход является одним из возможных ключей к решению проблемы недоинвестирования или переинвестирования, которая, в свою очередь, является следствием агентской проблемы в отношениях акционеров и менеджеров (т.е. несовпадения целей менеджеров (агентов) с целями акционеров (принципалов) вследствие различий их возможностей и/или степени информированности о будущих последствиях инвестиционного решения) [8]. Это связано с тем, что принятие во внимание менеджерской гибкости на стадии оценки проекта снизит уровень потенциального несоответствия целей менеджеров и акционеров и позволит принимать взвешенные решения с учетом снижения степени неопределенности во внешней среде.

\section{Заключение}

В данной статье проанализированы основные источники агентских издержек в инвестиционной деятельности компании, к которым относится недоинвестирование, диверсификация специфических рисков, переинвестирование и излишнее хеджирование. На практике агентская проблема оказывает существенное влияние на оценку инвестиционных решений и 
принятие решений по их реализации. Так, произвольная корректировка или использование нормативной ставки дисконтирования, наряду с использованием тредиционных методов оценки рисков инвестиционных проектов может привести к такому выбору портфеля инвестиционных проектов для реализации, который не будет максимально отвечать интересам собственни- ков. В результате появляется необходимость механизмов снижения данных агентских издержек на основе корректировки ставки дисконтирования на базе показателя Value at Risk или метода реальных опционов, применение которого позволяет по-другому посмотреть на оценку инвестиционного проекта, что также выравнивает интересы менеджмента и собственников.

\section{Библиографический список}

1. Бухвалов А.В. Теория фирмы и теория корпоративного управления // Вестник С.-Петерб. ун-та. Сер. Менеджмент. 2004. Т. 4. № 32. С. 99-117.

2. Бухвалов А.В. Корпоративное управление как объект научных исследований // Российский Журнал Менеджмента. 2005. Т. 3. № 3. С. 81-96.

3. Васильев С.И., Лукьянова А.Е. Методы оценки и управления рисками: применение концепции реальных опционов для оценки инвестиционных проектов в сфере недвижимости // Управление финансовыми рисками № 4 (44): 284-298.

4. Дамодаран А. Стратегический риск-менеджмент: принципы и методики. М.: ООО «И.Д. Вильямс», 2016. 496. с.

5. Дженсен М.К., Меклинг У.Х. Теория фирмы: поведение менеджеров, агентские издержки и структура собственности // Вестник С.-Петерб. ун-та. Сер. Менеджмент. 2004. Т. 8. № 4. С. 118-191.

6. Катькало В.С. Эволюция теории стратегического управления. Санкт-Петербург: Издательство «Высшая Школа Менеджмента», Издательский дом Санкт-Петербургского университета, 2011. Вып. 2-е издание. 546 c.

7. Либман А.В. Теоретические аспекты агентской проблемы в корпорации // Вестник С.-Петерб. ун-та. Сер. Менеджмент. 2005. Т. 1. С. 123-140.

8. Окулов В.Л. Инвестиционные решения компании в условиях неопределенности: подход с позиций риск-менеджмента // Вестник СПбГУ. Менеджмент. 2017. Т. 6. Вып. 2: 191-214.

9. Adner R., Levinthal $D$. What is not a real option: considering boundaries for the application of real options to business strategy. Academy of Management Review, 2004, Vol. 29, No. 1, pp. 74-85.

10. DeMarzo P.M., Duffie D. Corporate Incentives for Hedging and Hedge Accounting // Rev. Financ. Stud. 1995. vol. 8. No. 3. pp. 743-771.

11. Dzyuma $U$. Real options compared to traditional company valuation methods: possibilities and constraints of their use. Financial Internet Quarterly «e-Finance», 2012, Vol. 8., No. 2, pp. 51-68.

12. Graham J., Harvey C. How do CFOs make capital budgeting and capital structure decisions? Journal of Applied Corporate Finance, 2002, 15 (1): 8-23.

13. Graham J.R., Rogers D. A. Do Firms Hedge in Response to Tax Incentives? // J.Finance. 2002. vol. 57. No. 2. pp. 815-839.

14. Graham J.R., Smith C. W. Tax Incentives to Hedge // J. Finance. 1999. vol. 54. No. 6. pp. 2241-2262.

15. Lambert R. A. Executive Effort and Selection of Risky Projects // Rand J.Econ. 1986. vol. 17. No. 1. pp. 77-88.

16. Lim E.N.-K., Das S. S., Das A. Diversification strategy, capital structure, and the Asian financial crisis (1997-1998): evidence from Singapore firms // Strateg. Manag. J. 2009. vol. 30. No. 6. pp. 577-594.

17. Lovallo D.P., Sibony O. Distortions and deceptions in strategic decisions | McKinsey \&amp; Company // McKinsey Q. 2006. vol. February.

18. Myers S. C. Determinants of corporate borrowing // J. financ. econ. 1977. vol. 5. pp. 147-175.

19. Wang A., Halal W. Comparison of real asset valuation models: a literature review. International Journal of Business and Management, 2010, Vol. 5, No. 5, pp. 14-24. 